\title{
Asesinos, faites y bandoleros: cuando el vals peruano cantaba la trasgresión y la norma
}

\section{Killers, crooks and bandits: When Peruvian waltzes sang of social transgression}

\section{Gérard Borras ${ }^{1}$}

Universidad de Rennes 2. Rennes, Francia

\section{RESUMEN}

Este trabajo pretende rescatar del olvido las canciones cuyo tema es la trasgresión social en el Perú de inicios del siglo XX. Bandidos y criminales de todo orden fueron retratados en las letras de canciones, de tal manera que quedaron inmortalizados en los archivos, pero no alcanzaron más que a raspar la memoria colectiva en momentos posteriores. Muchas de estas obras fueron recogidas en El Cancionero de Lima, cuyo público era mayormente de los sectores populares urbanos letrados, de Lima y provincias. Estas canciones aparecían mezcladas con las letras de los éxitos del momento y refrescaban con su lenguaje festivo la vida cotidiana de la población peruana. La preocupación por tratar temas de este tipo se puede inferir de la atmósfera vivida en el cambio de siglo, cuando estas ciudades expresaron los cambios propios de un proceso de modernización que repercutió directamente en el tejido social urbano.

\section{PALABRAS CLAVE}

Lima, Perú, música popular, cancioneros, criminales y bandidos del siglo XX

1 Es profesor de estudios hispanoamericanos de la Universidad de Rennes 2. Dedica sus investigaciones a las relaciones entre música popular y sociedades en los países de América Latina y la zona andina en particular. Ha publicado, sobre estas temáticas, Lima, el vals y la canción criolla (1900-1936) y, con Fred Rohner, varias ediciones de archivos históricos de la música popular peruana. Ha sido secretario general del Instituto de las Américas en París y director del Instituto Francés de Estudios Andinos en Lima. 


\section{ABSTRACT}

This work aims to rescue from oblivion the songs whose underlying theme is social transgression in Peru during the early 20th century. Bandits and criminals of all kinds were portrayed in song lyrics, causing them to be immortalized in the nation's archives while remaining all but lost to the collective memory of subsequent generations. Many of these works were collected in the Lima Songbook, which mostly attracted a public composed of literate urban residents, either in Lima or beyond the capital. These songs influenced the hits of the time, bringing pleasure and entertainment through their witty language to the daily lives of ordinary Peruvians. The issues touched upon by such songs reflect the atmosphere of turn-of-thecentury urban Peru, with cities undergoing the changes inherent in the process of modernization, and their effects upon the social fabric.

\section{KEYWORDS}

Lima, Peru, folk music, songbook, criminals, 20th century bandits

Si confiamos en la memoria colectiva de los limeños o si examinamos la producción discográfica de discos de victrola de las primeras décadas del siglo XX y la posterior de los vinilos 45 o 33 r.p.m., los bandidos, los asesinos y los criminales no parecen haber inspirado a los autores y a los intérpretes de la canción popular de la costa peruana. Pongamos aparte el consabido vals «Luis Pardo» que canta al más famoso bandolero peruano; la canción parece haber ignorado una temática tan presente en otros países de lengua española. Los primeros tangos cantan a guapos y compadritos, los viejos corridos mexicanos relatan las epopeyas de revolucionarios bandoleros, los actuales cantan las exacciones de los narcos, las zarzuelas españolas evocaban los salteadores de camino y los malandrines; hasta la salsa no se olvidó del tema con, entre otras canciones, el extraordinario «Pedro Navaja», de Rubén Blades. Sin embargo, una búsqueda paciente nos ofrece sorpresas y las páginas de un pequeño cancionero demasiado tiempo olvidado permiten matizar la observación inicial.

Entre 1910 y 1940, aparecía todas las semanas El Cancionero de Lima, verdadero heredero del pliego de cordel. Se vendía en los mercados o en las calles de la capital peruana. Su público predilecto era popular, como lo indican su precio módico y el subtítulo: Semanario festivo popular. El cancionero publicaba cantables de zarzuelas, muy de moda en aquella 
época, pero también letras de canciones del repertorio internacional: boleros, corridos, rancheras, sones, congas, tangos, foxtrot, etc. Dedicaba también una parte importante de sus ocho páginas a la difusión de canciones populares de la costa y de Lima en particular. Con cuartetas y octosílabos estas canciones vienen a ser verdaderas crónicas de la vida cotidiana de la Ciudad de los Reyes. Cantaban evidentemente a los amores felices o frustrados, pero contaban también las transformaciones de la ciudad, la falta de alojamientos, la escasez de alimentos, los conflictos sociales, los problemas de frontera con el vecino chileno o colombiano, el surgimiento de la Patria Nueva del presidente Leguía o el del APRA de Haya de la Torre. Todo lo que de manera significativa sorprendía, consolidaba o perturbaba las relaciones sociales era captado (¿o creado?) por los editores de El Cancionero de Lima. Las canciones dedicadas a los maleantes de toda categoría y a sus exacciones no podían ser ausentes del repertorio. El espacio que ocupaban llama la atención hasta tal punto que podemos preguntarnos qué funciones cumplían en el espacio social en el que se difundían. Obviamente, percibimos en las composiciones el deseo de crear cierto sensacionalismo, de dar a leer al público lector u oyente detalles muy realistas, pero parece que lo esencial no radicaba en estos aspectos y que otras intenciones dibujaban el discurso subyacente de estas canciones.

\section{Asesinos y criminales}

Entre los temas privilegiados por El Cancionero de Lima figuraban los asesinatos. Poco a poco las ocho páginas del pequeño semanario se transformaban en verdadera crónica roja. Basta con hojear los primeros números de la serie 300 para darnos cuanta de que este género de canciones tenía éxito y que inspiraba a los compositores y autores.

301 El nuevo Caín

301 La muerte de Bedoya

304 Descubrimiento de un crimen

306 El suicidio de las Cómodas

320 El crimen de la calle Espaderos, declaración de los asesinos

322 Drama pasional de Mercaderes

326 El crimen del Callao

327 El crimen de la Victoria

340 El crimen del Barranco

Aunque nuestra información no está completa, disponemos de números suficientes para identificar una tendencia: el Cancionero se esmera en recoger y difundir este tipo de noticias. Estos crímenes conmueven, espantan a veces, sorprenden a menudo, ya que son, en una ciudad de 
dimensiones modestas todavía, la ruptura visible y muy cercana de un determinado orden social. Las canciones cuentan un comportamiento que se desvía de las normas y en este sentido son ambivalentes: dan miedo, pero fascinan. La canción y el cancionero dan otra existencia al acontecimiento poniéndolo en forma poética y melódica. Muchas veces hacen el relato del suceso recurriendo a la cuarteta y al octosílabo, pero subrayan también el aspecto insólito o sorprendente de la noticia relatada. No podemos considerarlos como meros soportes de una información: ofrecen también algo más, que es lo que el autor de la letra desea evidenciar.

La primera letra de la lista indicada arriba, «El nuevo Caín», fue publicada sin información complementaria (a qué género musical pertenece, con qué melodía debe ser interpretada, quién es el autor).

\section{El nuevo Caín}

Otro crimen nos deja

este terrible verano:

un malvado que por celos

apuñala a su hermano.

El caso es que un Palomino con su hermano que es Medina

reñían a las puñadas

del camal en una esquina.

Y boxeaban nada menos sin dar su brazo a torcer, por estar enamorados de una misma mujer.

En el curso de la lucha Palomino algo entendido le dio feroz puntapié que lo dejó sin sentido.

Creyéndolo casi muerto se dio a la fuga el bandido pensando escapar así de poder ser aprehendido

La Policía que es lista en casos como el presente cumpliendo con sus deberes le dio caza al delincuente. 
Al sitio de la pelea condujeron al malvado, donde todavía estaba su pobre hermano, privado.

Palomino al verlo así muy lejos de arrepentirse $y$ sin que los policiales pudieran apercibirse,

Sacó un puñal que tenía muy oculto de antemano se abalanzó y se le hundió en el cuerpo de su hermano.

Luego blandiendo el puñal acometió a los guardianes, llenándolos de improperios y llamándolos rufianes.

Después de algunos esfuerzos fue reducido el matón, llevado cual merecía a purgar en la prisión.

La originalidad del tema radica en este crimen que involucra a dos hermanos que pelean por el amor de una misma mujer. La ruptura del orden es doble: los vínculos fraternales no son suficientes para representar valores morales supremos que hubieran podido impedir el conflicto. Por otra parte, el fratricida llevado por la Policía en el lugar de la pelea, muy lejos de apiadarse, saca la navaja que escondía y se ensaña con su hermano.

Las 10 cuartetas de octosílabos ofrecen la narración de la escena y sus diferentes momentos según un esquema muy conocido, pero la última estrofa concluye mostrando que la moral y el orden social se han preservado. Esta referencia al «buen comportamiento» estaba ya presente en la canción cuando el autor rendía un señalado homenaje a las fuerzas del orden:

La Policía que es lista

en casos como el presente cumpliendo con sus deberes le dio caza al delincuente.

Dicho de otro modo, percibimos una de las constantes de las canciones publicadas. En sus versos los autores insisten en el horror de los 
crímenes, en la ruptura social que significa el comportamiento de los asesinos, para ofrecer como telón de fondo a la sociedad limeña y, en particular, a los sectores sociales en los que se difundían estas canciones, un discurso de normas y de comportamientos ciudadanos. Es lo que podemos leer también en este vals publicado en El Cancionero de Lima, nro. 340:

\section{La captura de Cata}

Cata, que es un gran malvado,

a una pobre anciana

en barranco estranguló, y por no ser denunciado

a la infeliz muchacha también él la hirió.

Ya encerrado está entre rejas el bandido, que pronto recibirá el castigo merecido.

Hoy toda la sociedad da un voto de aplauso a esta gran autoridad, que con su sagacidad descubrió al criminal.

En otro número, «El crimen de la calle Espaderos» describe con gran cantidad de detalles los diferentes momentos del crimen, el comportamiento inhumano de la instigadora que usa de sus encantos para que su víctima caiga en la trampa que había premeditado con su cómplice.

El crimen de la calle de Espaderos ${ }^{2}$

(Declaración de los asesinos)

Ya conocen los lectores

el crimen sensacional, con sus miterios y horrores

que alarmó á la capital, La Yolanda y el Durán son los dos protagonistas, personas ambas muy listas que combinaron el plan. Ella fue amante de Goldz 
y su dinero le dio;

disgustáronse los dos

y la venganza surgió.

Los celos la hicieron presa

de un desprecio que sufrió,

revestida de maleza

por asesinarlo optó,

Buscó cómplice, a Castillo

que de Goldz fue su empleado,

y que por ser algo pillo

de la casa fue expulsado.

Durán guardaba rencor

por el que fue su patrón,

y aprovechó la ocasión

al demostrar su valor.

Como lo es de suponer,

tuvieron una entrevista

entre el hombre y la mujer,

quedó la venganza lista.

Ella para apoderarse

de la persona de Goldz,

simuló reconciliarse

y en paz quedaron los dos.

Para practicar su infamia

esta a Durán ocultó

por debajo de la cama

donde el momento esperó.

Muy pronto Goldz se durmió

caneado de sus labores,

y entonces, pues, comenzó

el crimen con sus horrores.

Yolanda una ficha empuñó

que una tal Cruz le llevara,

y el primer golpe asestó

a Goldz que estaba en la cama.

Ella al punto se aterró

y el hacha pasó a Durán

con la que a Goldz victimó

coronando el negro plan.

Durán las joyas robó

del dueño de la pensión,

presto a la fuga se dio 
después de su inicua acción.

El crimen fue descubierto

se hicieron varias prisiones,

se dio sepultura al muerto

y siguieron las gestiones.

Durán fugarse intentó

pero su mala ventura,

fue encontrarse con Portura

quien de hecho lo descubrió.

Un gran brillante ofreció

al señor Portura en venta,

y este en el acto pensó

que era un cómplice de cuenta.

Con la joya se quedó

y dejó pasar el día,

llamando a la Policía

y ante ella lo delató.

Ahí mismo lo hicieron preso

y ante Yolanda Ilevado,

después de haberse careado

quedó convicto y confeso.

Yolanda al ver a Durán

de pronto palideció

y con malicioso afán

reconocerlo negó.

Durán, pues, la descubrió

después de largo careo,

y Yolanda declaró

ser la cómplice del reo.

Yolanda es joven y hermosa, chilena y de alma muy mala, de vida - dicen - dudosa

y vistió siempre con gala.

Con el tradicional octosílabo el autor de la canción nos hace compartir la escena, pone de relieve los aspectos más malévolos de la criminal, de la que descubrimos que, además de ser guapa, perversa de poca moral, es de origen chileno. ¡No faltaba más!

En otra canción publicada por El Cancionero de Lima, el autor se sorprende del móvil del asesinato, prefigurado ya en el título: «El crimen de la calle de Espíritu Santo por entonar una canción». Con una serie de tres décimas de forma muy académica, describe las circunstancias del crimen, 
subraya el carácter totalmente incomprensible del asesinato y sugiere una explicación:

\section{El crimen de la calle de Espíritu Santo}

\section{Por entonar una canción}

(La canción fatal)

Ya se acabó la dicha para mí

Mis ojos se cansaron de llorar

Cuando de ti me ausente, viejo amor,

Inútilmente habíasme de buscar.

A una mujer por cantar

Esta copla del olvido

Su celoso y mal marido

La ha llegado a asesinar.

Esto se acaba de pasar,

Causando a todos espanto,

En el Espíritu Santo

Que es la calle más pacífica,

Una mañana magnífica,

Solamente por un canto.

Pues se le ocurrió entonar,

Preparando el desayuno

Esa canción que a ninguno

Mal le podría sonar.

Ella quiso amenizar

Así su trabajo, pero

Al marido majadero

No le cuadra la canción...

Y le hunde en el corazón

Puñal grande de acero...

El criminal que es un taita

Peor que el del arrabal;

Padece de un grave mal

Y dizque se llama Isaac Maita

A las mujeres engaita,

Como también engaitó

A esa infeliz que mató

Llamada María Lara,

Porque ¡cosa rara!

Una canción le cantó 
Una vez más estamos más allá de la norma, ya que no solo el asesino está fuera de la ley, sino que además es loco: «padece de un grave mal». Aparece entonces la dimensión ideológica de este tipo de producción; se trata de validar una forma de orden social y de dibujar, bajo diferentes formas y modalidades, mensajes cuya meta es, a la larga, convencer a amplios sectores sociales de que la «buena conducta» pasa por la aceptación de cierto statu quo social. Es una de las lecturas propuestas por Steve Stein en su artículo sobre los valores de la clase obrera en Lima a principios del siglo XX. Varias de las afirmaciones de Stein hubieran merecido más prudencia; sus generalizaciones descansan en un corpus demasiado reducido, pero es uno de los primeros en señalar la dimensión ideológica de la canción popular de la costa y del vals criollo en la Lima de aquel entonces.

Si los ejemplos que acabamos de presentar solo bosquejan la temática, el que vamos a analizar ahora la hacen aún más evidente. En 1916, un joven criado asesinaba a sus patrones, los esposos Ibarra. La temprana edad del criminal, el hecho de que matara a dos personas con cuchillo y la total ausencia de remordimientos tuvieron un eco considerable en la prensa y la sociedad limeña. Como muchas veces en casos similares, la musa popular creó una canción para relatar y comentar el acontecimiento, y El Cancionero de Lima la publicó en el número 269, pero es, no cabe duda, la nueva edición de una composición más antigua, ya que semanas antes el número 249, cuya portada presentamos en estas páginas, había dado mucha importancia al acontecimiento con la publicación de varias canciones. Este vals no se presenta bajo la forma de una requisitoria; intenta más bien dar una primera explicación al crimen:

\author{
Alejandrino Montes ${ }^{3}$ \\ Alejandrino Montes \\ el joven criminal \\ que mató a sus patrones \\ haciéndose fatal; \\ él lo hizo por venganza, \\ según lo declaró, \\ al repetir el crimen \\ cómo los victimó.
}

Las interpretaciones en torno a las motivaciones reales del asesino no faltan. Sin embargo, sin que podamos estar seguros, la venganza era un móvil verosímil. En efecto, en un análisis sobre el trabajo de los niños en 
Lima, el historiador Ricardo Portocarrero indica que los castigos infligidos y las terribles condiciones de trabajo podían explicar el crimen 4 .

Son versiones diferentes las que encontramos en el número 249 de $E I$ Cancionero de Lima. El espacio dedicado al acontecimiento es ya una indicación del impacto que había tenido entre la población limeña. No son menos de 31 cuartetas que en tres canciones tratan del tema. La primera es una sorprendente ficción que hace intervenir a un célebre hipnotizador y que se producía en los más famosos teatros de América Latina. Se trata de sacar de manera casi mágica la confesión del criminal, que, hasta entonces, no había sido muy locuaz. Y la respuesta (supuestamente auténtica, ya que fue pronunciada fuera del control de la voluntad) es muy diferente de la versión anterior:

\section{Declaración de Montes a Onofroff ${ }^{5}$}

-Sí, señor, yo los maté, por envidia a su riqueza.

- ¿Qué esperaba de esa vileza?

- Ser rico, me figuré,

yo envidiaba a mi patrón,

yo me quería igualar

y cambiar de condición

para pasearme y mandar.

[...]

Porque rico se soñó

Asesinó a sus patrones

Le sed de oro lo llevó

Al crimen con sus horrores.

He aquí el verdadero crimen de Alejandrino Montes: la ambición, la codicia, el deseo de conseguir las ventajas de otra clase social o, por lo menos, vivir las representaciones que de ellas tenía: «y cambiar de condición para pasearme y mandar». De aquí proviene el juicio definitivo de Onofroff:

4 «Las relaciones entre patrones y sirvientes no se habían modificado desde su inicio en el siglo XIX. La mayoría de estas labores eran realizadas por niños traídos del campo, particularmente de las haciendas, cuyos propietarios residían en Lima. Estos no solo eran traídos a trabajar en sus casas, sino también en las de sus amigos y compadres. De que las situaciones y abusos y maltratos no habían cambiado lo podemos ver en el caso de Alejandrino Montes, quien [...] asesinó a los dueños de la casa en donde trabajaba, cansado de la situación. En este caso se vio involucrada su hermana Fabiana, quien también laboraba junto a él» (Portocarrero, 1998, p. 62).

5 El Cancionero de Lima, nro. 249. 
Es un chico degenerado,

Ambicioso y sin temor

Es un desequilibrado

Digno de justo temor.

Esta ambición produce un desorden incontrolable, pone en peligro los valores de la sociedad y, por lo tanto, merece un justo castigo. Los demás textos del número 249 van aún más allá en sus mensajes implícitos. El primero lleva el título siguiente: «Entrevista de Alejandrino y su padre», y cuenta la visita que hace el padre a su hijo encarcelado en un calabozo. El hijo se muestra insensible en un primer momento («ni el más liviano suspiro»), pero después la presencia del padre y de los valores que representa lo devuelven a la normalidad («estrecha en un fuerte abrazo / a su padre el infeliz»). Después de la confesión («del crimen soy el autor»), reaparece el carácter malvado del personaje:

Ni una lágrima vertió

ese hijo desventurado,

al recuerdo del pasado

ni menos se conmovió.

Luego, la canción pone de relieve la distancia entre un padre que de manera paciente aguantó los rigores de la existencia sin rebelarse por eso y un hijo totalmente ajeno a estos comportamientos, los que, aunque muy duros, confieren respetabilidad:

Aunque soy un hombre honrado

Que vivo de mi trabajo

También fui calumniado

Y tratado como estropajo.

El último texto publicado en este número 249 es la tercera y última etapa de la historia de Alejandrino Montes, estando él vivo todavía. El autor del vals «Montes y su padre» entrega una letra escrita en primera persona y es Alejandrino el que se dirige a su padre, pero de manera totalmente diferente de las veces anteriores:

\section{Montes y su padre}

(Música de «La despedida de Arciniega»)

Aquí me tienes, padre querido,

Entre estas rejas encarcelado,

Aquí mi crimen audaz expío

Yo a 15 años soy condenado. 
La suerte fiera me echó sus garras

Y en asesino me convirtió,

Mis horas, padre, son muy amargas

Pero esta culpa la tengo yo.

De Dios espero solo el perdón

También el tuyo, padre querido, Mientras que viva en la prisión

¡ay!, no me eche en el olvido.

Yo de ese crimen soy el culpable

Y si me castigan es con razón

No llores por tu hijo, querido padre,

Que mucho sufre mi corazón.

Cuando regreses a mi terruño

Dile a mi madre que ruegue a Dios,

Por ese hijo que el infortunio

Quizá por siempre lo separó.

Hijo de mi alma, hijo querido, Me voy llorando tu desventura, Yo te perdono si arrepentido

Llegas un día a ser sufrido.

Muy lejos de la insensibilidad y de la rebelión, es un ser consciente de su culpa que se encomienda a Dios («De Dios espero solo el perdón»). Asume su error y admite la justicia de los hombres. Solicita la ayuda de su madre («Dile a mi madre que ruegue a Dios / por ese hijo») y, tras un breve instante, vuelve a crear el núcleo familiar virtuoso del que se había separado. Desde el fondo de su calabozo, por la gracia de la justicia de los hombres y de los valores religiosos y familiares, vuelve a ser el individuo que nunca hubiera tenido dejar de existir.

Apenas dos años después, el número 356 de El Cancionero de Lima publica otro vals, «La muerte de Alejandrino Montes», en el que se anuncia asimismo la defunción de su hermana Fabiana. La información nos deja imaginar las terribles condiciones que tuvieron que vivir estos prisioneros: la justicia podía ser también una venganza. Al final, estas canciones quieren tener una función pedagógica: prescriben un comportamiento normal, para no decir normativo. Hay en esa postura una reminiscencia del exemplum, tan importante en las prácticas religiosas del antiguo colonizador. De manera implícita, definen el marco de la conducta ejemplar 
o erigen el conformismo en una de las principales virtudes del comportamiento social'.

\section{Faites y bandoleros}

Muchas otras canciones del pequeño cancionero limeño hacen el relato y comentan varios de los acontecimientos que perturban el orden social. Pero, a diferencia de las situaciones anteriores, los actores tienen una identidad y un estatuto específico en la sociedad peruana. Sus funciones, sus acciones y sus biografías les han conferido una fama que la tradición oral y la canción popular contribuyeron también a construir. Podríamos oponer dos grupos de individuos dentro de los que vamos a hablar. Por una parte, los bandoleros que viven su existencia fuera de la ciudad; por otra parte, los faites que, al contrario, hacen de la ciudad y del barrio el lugar privilegiado de sus actividades. La realidad es sin ninguna duda mucho más compleja y las fronteras no son tan estrictas, sobre todo en lo que concierne a los bandoleros que tenían sus espacios en las ciudades. Pero el teatro de sus acciones estaba muy claramente identificado.

Los faites o faiteman son personajes que ofrecen un parentesco evidente con el guapo porteño. El faite es un individuo más bien susceptible, siempre dispuesto a sacar su chaveta; a veces vive de la protección que ofrece a ciertas damas y, en algunos casos, a ciertos personajes políticos. Pertenece al mundo de la delincuencia, en el que las reglas del honor y de la valentía sustituyen a las que se aplican a los demás.

El nombre y la existencia de estos personajes han dejado en Lima mucho menos recuerdos que en Buenos Aires, donde el tango y la milonga se encargaron de crearles presencia y memoria. Sobreviven solamente a través un episodio del que la canción supo guardar el recuerdo. El 2 de mayo de 1915, dos famosos faites se citan para ajustar cuentas pendientes con la punta y el filo de sus chavetas. La talla, fuerza y bravura (y una «hoja de servicios») de Tirifilo lo convierten en el más famoso y temido faite de Malambo, barrio predilecto del hampa limeño. Carita, mucho más joven y de estatura mucho más modesta, parece disponer únicamente de su arrojo y su habilidad en el manejo de su arma. La suerte estaba echada y muy pocos apostaban a favor de Carita. Sin embargo, lo que ocurrió fue lo improbable. A pesar de las profundas heridas recibidas en el combate, Carita hundió su arma en el corazón de su rival, que murió al instante.

6 «El conformismo es una fuente inagotable de felicidad; los grandes retrocesos en la vida no vulneran los corazones de aquellos que saben conformarse; la conformidad ofrece los mayores beneficios, porque le permite a uno evitar inquietantes preocupaciones y tenebrosas irritaciones». Frase extraída de un periódico de tendencia anarcosindicalista, El Obrero Textil, del 1 de mayo de 1925. El autor criticó ese comportamiento. Citado por Stein, 1986. 
No era cosa nueva que dos malandrines ajustasen sus cuentas de tal forma; el episodio no es original. Tuvo, sin embargo, un eco muy potente en los medios populares de donde habían salido los dos contrincantes y en los periódicos destinados más bien a las élites de la capital. ¿Qué cosa tan excepcional tenía este combate? En realidad, presenta una serie de elementos que contribuyen a la fabricación de una leyenda. Los dos «héroes» son excepcionales, uno por su fuerza y su fama, el otro por su bravura, que le permite enfrentarse con el más temido de los faites de Lima. ¿Pertenecen a los márgenes de la sociedad y no usan ni obedecen los códigos y valores del ciudadano común? En eso también son excepcionales y, por lo tanto, despiertan miedo y admiración. Viene después el aspecto teatral del combate, que simbólicamente se desarrolla a orillas de la ciudad (en uno de los muladares de la capital), cerca de la vía de trenes, cuyos rieles dibujan los límites del espacio urbano. La hora tampoco es común: el combate se realiza en plena noche después que la luna aparece en el cielo limeño. A pesar del origen plebeyo de los actores, el combate se desarrolla según un ritual en el que los códigos del honor se respetan. Percibimos entonces este juego permanente entre lo social y la parte marginal de lo social. Por fin tenemos en combate en sí mismo y su resultado: Carita recibe tantas heridas como el cuento necesita etapas para desarrollarse, y asistimos en el sentido más puro de la palabra al coup de théâtre: el más débil, el que tiene menos experiencia, el que nadie o casi nadie veía salir vencedor, asesta un golpe mortal a su adversario.

Podemos leer este relato en algunas canciones populares que recogimos gracias a los cancioneros y a la revista Variedades: «La muerte de Tirifilo (a)», «La muerte de Tirifilo (b)»y «Sangre criolla». Podemos subrayar el parentesco del primer texto en particular con los viejos romances españoles de la Reconquista:

La muerte de Tirifilo (a)

Vals de actualidad

Música del vals «Varela»

Era Cipriano Moreno

de carácter singular

por sus múltiples hazañas

notable en el Tajamar;

sus instintos depravados

bien pronto dio a conocer

con los pobres desgraciados

que en los barrios apartados

cayeron en su poder. 
¡Oh! Famoso Tirifilo

que la vida te ha costado

ese lance inesperado

donde fuiste muy tranquilo.

Una noche que bebiendo

estaban varios matones

con las copas fue subiendo

de punto las discusiones;

Tirifilo apareció

en el café donde estaban

pues tranquilo disputaban

y sus hazañas contaban

cuando Wilman lo retó.

Oh, famoso Tirifilo...

Ya en el sitio designado

la pelea comenzó

Wilman casi desmayado

varios cortes recibió;

acosado Tirifilo

con un riel se tropezó

tras Wilman le asestó

una feroz puñalada

que el pulmón le atravesó.

Oh, famoso Tirifilo...

Así terminó su vida

el infeliz Tirifilo

que ha dejado sorprendida

a la sociedad;

pues por sus malas hazañas

seguro la causa ha sido

de la muerte que ha tenido,

llegando a ser muy temido

por su terrible actuación.

Quien a cuchillo mata

a cuchillo muere.

Pero si estas canciones ofrecen relatos más o menos idénticos, no brindan puntos de vista similares sobre los rivales y sus actuaciones. El primer 
texto dibuja rápidamente la escala de valores que van a servir de marco para la lectura del acontecimiento: Cipriano Moreno, alias Tirifilo, está descrito a lo largo del texto como un individuo cuyo comportamiento moral es inaceptable (la cuarta estrofa en particular). La moraleja que concluye el texto marca el justo retorno a los valores que, como ley natural, se aplican a toda la humanidad, y dibujan así los límites del comportamiento social («Quien a cuchillo mata / a cuchillo muere»). De tal forma la canción establece una conducta normativa y no es en ninguna manera una glorificación de los personajes, ni siquiera de Carita, que pone fin a las exacciones de Tirifilo. El segundo texto no propone una lectura diferente:

Ni siquiera un leve acento

de dolor se oye cercano

Todos dicen: fue un villano

que vivió para tormento.

Es un enemigo menos

de la pobre humanidad

que lleva a la eternidad

el estigma que sabemos.

El tercer texto, en cambio, propone un punto de vista bastante diferente $y$, cosa que sorprende, está publicado por la revista Variedades, que nunca disimuló sus opiniones para con la popular criolla. En uno de sus números de mayo de 1915, sin poder escapar a la magnitud del evento, los periodistas publican la información siguiendo la tradición de la nota roja y, para dar más fuerza al artículo, completan con una foto titulada «Reconstrucción gráfica de la escena del duelo en el Tajamar. El emocionante momento en que Carita hunde la chaveta en el cuerpo de Tirifilo cuando este tropezó con la vía férrea».

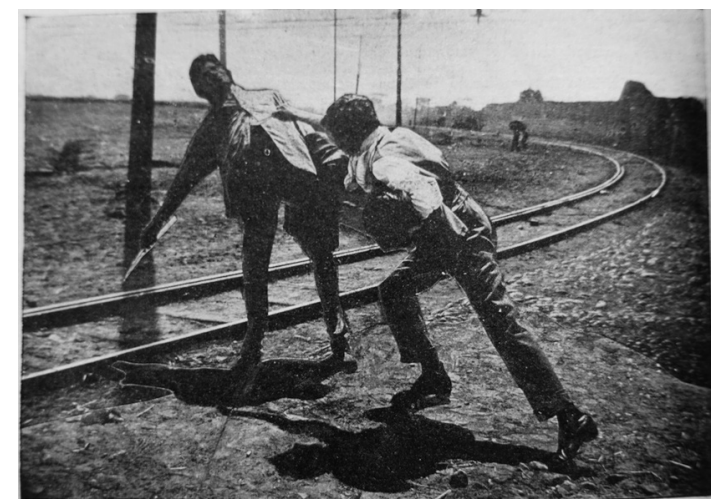

FIGURA 1. Reconstrucción gráfica de la escena del duelo en el Tajamar. 
En la conclusión del artículo, el periodista añade: «Dentro de poco la musa anónima impresionada con el hecho trágico rimará alguna ingenua canción y en la música criolla se elevará alguna marinera o algún tondero o vals típico en que figuren los héroes de la jornada de las chavetas. Y esa música será seguramente triste» ${ }^{7}$.

En el número que sigue parece un texto titulado «El último duelo criollo y la musa popular» junto con la letra de la canción «Sangre criolla»:

\section{El último duelo criollo y la musa popular}

Como lo presumiéramos en nuestro número anterior, al dar información gráfica del sensacional duelo criollo entre Tirifilo y Carita, la musa popular se ha inspirado en aquel duelo sangriento y ha creado unas coplas cantadas con la música conocida con que aquí se canta las coplas dedicadas a la memoria del bandido nacional Luis Pardo. Como una verdadera curiosidad y por tratarse de una confirmación original de lo que dijéramos en nuestro anterior número, reproducimos aquí los versos que se han estado vendiendo por las calles de Lima en los últimos días.

Percibimos en este discurso dinámicas muy particulares. Si damos fe a lo que dice la revista, los periodistas habían anticipado el evento y confiado en que la lira popular iba a crear canciones cantando los hechos y ensalzando a sus «héroes». Cuando la revista publica la canción «Sangre criolla» una semana más tarde, la revista se autofelicita por su perspicacia («una confirmación original de lo que dijéramos en nuestro anterior número»).

Hay una cosa cierta: estas canciones se difundieron en el espacio limeño y su existencia muestra a las claras que los compositores podían comentar muy rápidamente un evento importante. Constatamos también que la revista Variedades no logra situarse en el mismo nivel de los hechos que relata la canción popular. Según el periodista que escribe el artículo, la revista tan solo transcribe una canción que se cantaba en las calles de Lima y la presenta a sus lectores como algo muy curioso. Podemos medir entonces las distancias que separan dos mundos: sin que podamos estar seguros, varios elementos parecen indicar que el texto "Sangre criolla» no es creación de la musa popular, como lo pretende la revista. Varios elementos evidencian cierta exterioridad con los hechos relatados. Lo percibimos primero en la tipografía: lo que supuestamente pertenece al universo de los «otros», en particular su jerga, está escrito en bastardillas para

7 Variedades, 8 de mayo de 1915, nro. 375. 
indicar claramente que se trata de un discurso que no es el de los lectores habituales de la revista:
La gente los conocía como matones de oficio, pues sabía que los dos eran mozos divertidos y le paraban los machos a todo hijo de vecino. Faitemanes como nadie, valientes y decididos mozos chuchos, ipura yema!, la flor de lo mejorcito.

Otro indicio: la canción «Sangre criolla» no ofrece prescripciones morales como las que leíamos en las que publicaba El Cancionero de Lima. Al contrario, la última estrofa parece reconocer los valores del mundo de la delincuencia:

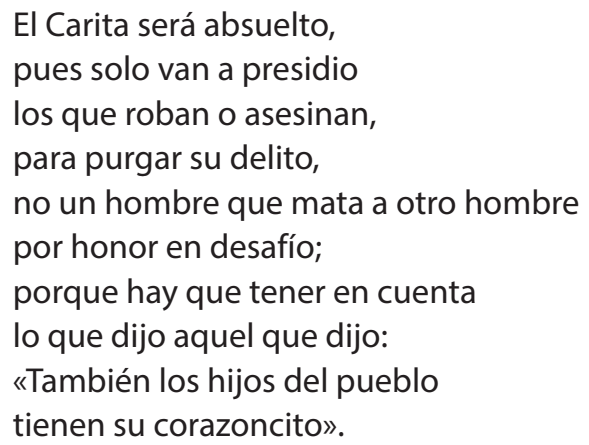

Los bandoleros no son específicos de Perú y el siglo XIX español tuvo en este campo a sus héroes. En América Latina los salteadores de caminos contribuyeron a dar la dimensión épica de la historia de los países que acababan de conquistar su independencia. Muchos de los que habían encontrado en los conflictos de la independencia espacios que les abrían una nueva vida que rompía con la rigidez de la sociedad colonial. Una vez terminados los conflictos, muchos no aceptaron el retorno a la «otra vida» $y$ vieron en el bandolerismo una manera de mantener la libertad y los espacios que acababan de conseguir. Este fenómeno fue muy fuerte 
en el Perú y Jean Piel nos dejó testimonios que no dejan dudas sobre la violencia y la crueldad con las cuales podían actuar estos personajes ${ }^{8}$.

Sin embargo, a pesar de estas fechorías, la figura del bandolero tiene una dimensión sorprendente. Si bien se lo presenta como un ladrón que vive al margen de la sociedad y despoja a sus víctimas, no es por lo tanto un individuo sin normas y valores. A semejanza de Robin Hood o de El Tempranillo, se lo presenta a menudo como a un ser generoso que ampara a la viuda y al huérfano y reparte su botín. Numerosas canciones han cantado las acciones de tal o cual bandolero, pero a principios del siglo XX se cantó y publicó en Lima un vals que muy pronto ocultó a todos los que cantaban temas similares. «El canto de Luis Pardo» o «La canción de Luis Pardo», a menudo conocida como «La andarita», tuvo un «ruidoso éxito», para emplear la terminología del Cancionero.

Esta canción empieza a conocerse en 1909, después de la muerte, o más exactamente la ejecución, del bandolero que había alborotado el departamento de Áncash a principios del siglo XX. Publicada en cancioneros, en la prensa de la alta sociedad, grabada por la Víctor TM en los años $1920^{\circ}$, viene a ser bastante rápidamente un clásico de la canción popular de la costa peruana y sigue siendo un clásico del repertorio contemporáneo de los cantores criollos. Jorge Basadre señala que en 1927 se hizo una película que celebraba el famoso bandolero ${ }^{10}$. ¿Cómo entender el impacto y el éxito de esta canción en la sociedad de la época? Sin duda porque era mucho más que el relato de las fechorías de un salteador de caminos.

«El canto de Luis Pardo» está compuesto de 11 décimas cuya historia es un tanto misteriosa. Fueron publicadas por primera vez el 23 de setiembre de 1909 en la revista Integridad, dirigida en aquel entonces por EI Tunante Abelardo Gamarra, figura legendaria del criollismo, pero que en ningún momento reconoció ser el autor de estos versos. Varios rumores

8 «A veces este bandolerismo viene acompañado con actos de impresionante crueldad que lo acerca al fenómeno del bandidaje. En junio de 1834, una pandilla detiene a un chasqui indio en el camino de Huacho a Lima. Lo despojan de su cartera y de manera totalmente gratuita le revientan los ojos con una navaja y lo abandonan ciego en medio del desierto. Si una víctima de un robo intenta cualquier resistencia, es ejecutada acto seguido, a quemarropa. Estas violencias exasperadas pero frecuentes son la señal evidente de una ruptura total con las instituciones dominantes: los que cometen semejantes fechorías no tienen nada que perder. Desarraigados, sin estatuto jurídico o económico, los bandoleros detenidos por la policía o el ejército no esperan sino la tortura durante el sumario y la muerte» (Piel, 1982, p. 8).

9 «Luis Pardo»: Gamarra y Marini (autor: L. Yerovi). VTM nro. 73633-A. Por razones de duración, el valor registrado no consideró las 11 décimas. Solo se canta la primera, la quinta, la novena y la undécima estrofa.

10 Enrique Cornejo Villanueva, propietario de la fábrica nacional de calzado Record, tuvo en 1927 la iniciativa de producir una película nacional sobre la leyenda del bandolero Luis Pardo. Se estrenó el 27 de octubre de 1927 en el Teatro Excelsior y fue repuesta dos días en funciones dobles (Basadre, 1980, p. 4656). 


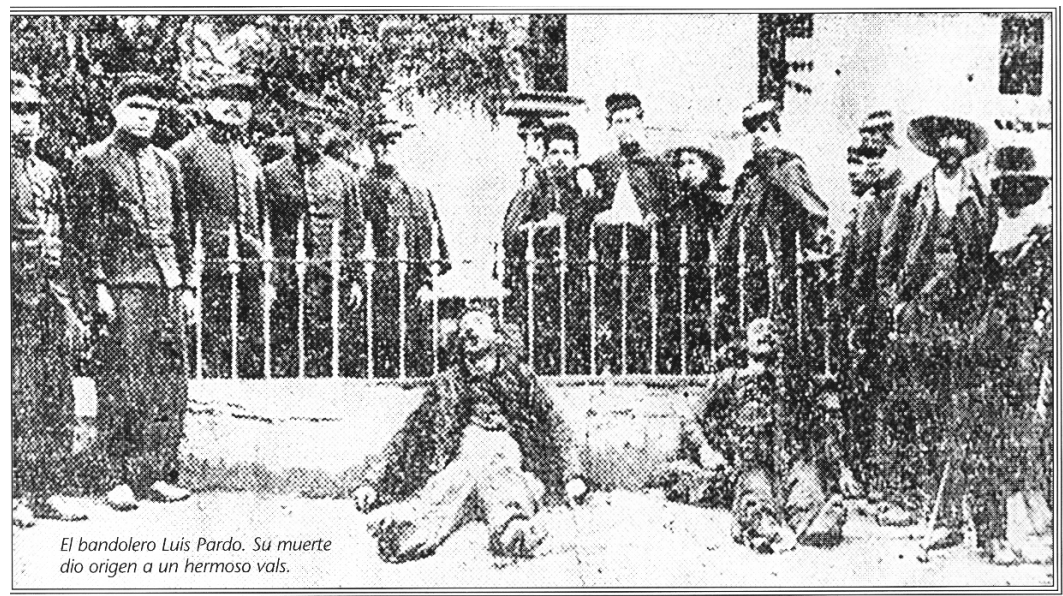

FIGURA 2. La muerte de Luis Pardo

decían que habían sido encontrados en un banco en un parque público y que se llevaron a Gamarra, que decidió publicarlas. Otros afirman que el poema es de Leonidas Yerovi padre, y, con razón o sin ella, la Víctor grabó «Luis Pardo» mencionándolo como autor. No hay nada cierto al respecto, pero podemos notar que el anonimato siente perfectamente a este tipo de composición que quiere adoptar la forma y las características de la canción popular.

Este poema no cuenta, como los textos que acabamos de presentar, un acontecimiento particular, sino el monólogo que permite al lector y al oyente de saber mejor quién es este personaje Luis Pardo, sus valores y el porqué de sus acciones de bandolero. La primera estrofa bosqueja un personaje sensible, a la vez enamorado y romántico, y también hijo nostálgico de este amor filial del que ha sido privado demasiado tempranamente:

Ven acá, mi compañera;

ven tú, mi dulce andarita, tú sola, sola, solita, que me traes la quimera de aquella mi edad primera, que en el campo deslizada, junto a mi madre amada y de mi padre querido, era semejante al nido que hace el ave en la enramada.

En la segunda décima descubrimos por qué este individuo con sentimientos tan respetables rechaza el orden establecido y se hace bandolero: 
A mi padre lo mataron, mi madre murió de pena;

ella, tan buena, ¡tan buena!

¡Ellos que tanto me amaron!

Estamos muy lejos de la imagen del bruto incapaz de emociones. Paulatinamente, como usando la técnica del negativo fotográfico, el poeta construye la imagen del personaje, bandolero, por cierto, pero que concentra todas las virtudes de las que están desprovistas las autoridades que lo persiguen. Su rebelión cobra entonces una nueva dimensión. El bandolero viene a ser la personificación del verdadero derecho y de la verdadera justicia:

De entonces, ¿qué hube de hacer?

Odiar a los que me odiaron;

matar a los que mataron

lo que era el ser de mi ser;

en torno mío no ver

sino la maldad humana;

esa maldad cruel, insana,

que con el débil se estrella,

que al desvalido atropella

y de su crimen se ufana.

Tal personaje no podía ser egoísta y su experiencia personal adquiere una dimensión colectiva, ya que, como todo ser generoso que ha vivido la injusticia en carne propia, asume sus responsabilidades morales y se transforma en defensor de los oprimidos:

Por eso yo quiero al niño;

por eso yo amo al anciano;

$y$ al pobre indio, que es mi hermano,

le doy todo mi cariño.

No tengo el alma de armiño

cuando sé que se le explota;

toda mi cólera brota

para su opresor, me indigna

como la araña maligna

que sé aplastar con mi bota.

La parte que concierne la defensa del indio tiene que ver con este periodo en el que el indigenismo desde González Prada empezó a ganar espacios es la sociedad peruana. Poco a poco, vemos cómo la narración 
va más allá de la simple historia de las exacciones de un bandolero. La canción alcanza otro registro de significación. La canción es, de manera paradójica, un catálogo de comportamientos cívicos y morales asumidos por un personaje que se puso en los márgenes de sociedad e instituciones de las que condena la conducta. En este periodo de la historia peruana conocida, como República Aristocrática, el personaje de Luis Pardo viene a ser la encarnación de los valores que un Estado verdaderamente justo tendría que defender. En este sentido, prefigura el «salvador político». ¿No es lo que propone Augusto B. Leguía cuando propone su proyecto de Patria Nueva? Estamos muy lejos del bandolero y entendemos mejor la reacción de ciertos sectores sociales para con esta canción. La revista Variedades hablaba de:

Luis Pardo, aquel bandido de musical recordación, cuyo espíritu vaga hoy en los malos versos de una musiquita popular, diciendo sus hazañas y sus generosidades, entre el vaivén de una tonada mezcla de valse cursi y de marinera descocada ${ }^{11}$.

Es muy difícil ser bandolero después de Luis Pardo. Ningún otro suscitó tal entusiasmo y tratamiento musical y poético similar. El bandolero parece perder todo tipo de prestigio y vuelve a ser un bandido cualquiera, aunque sus malas acciones provoquen emociones fuertes entre la población. El Cancionero de Lima se hace regularmente el eco de estos eventos aprovechando de las innovaciones técnicas que puede usar la imprenta popular. El cancionero usa la fotografía de manera corriente a partir del número 700 y puede así dar más fuerza a su mensaje. El número 956

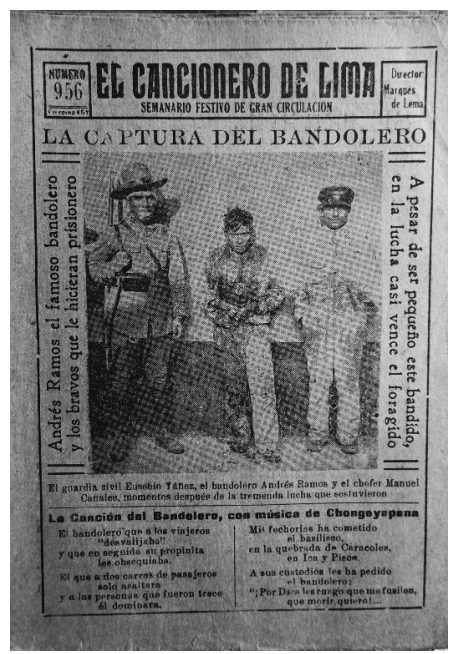

FIGURA 3. La captura del bandolero

11 Variedades, nro. 204, 27 de enero de 1912. 
muestra que estamos mucho más en una lógica de información periodística que en el registro habitual de un cancionero. Lo que importa es la noticia sensacional que contribuye a construir la fotografía, mostrando al bandolero ensangrentado entre los dos héroes que lo capturaron como si fuera una bestia salvaje.

"La canción del bandolero» ya no es el objeto central de la comunicación, como hubiéramos podido encontrar en un «verdadero cancionero». Encontramos una técnica similar en el número 979: la mirada del lector viene captada por la fotografía del bandolero muerto en unas andas.

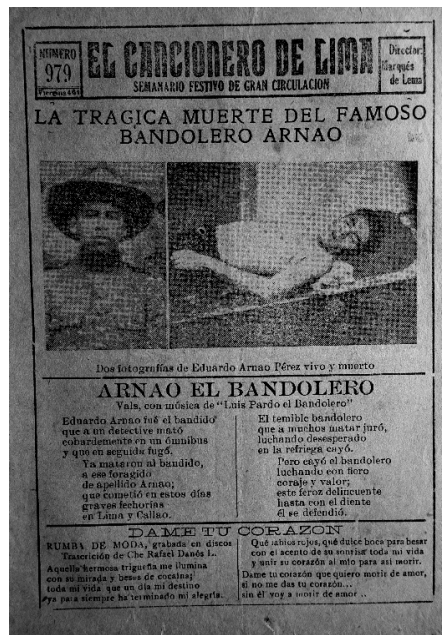

FIGURA 4. La trágica muerte del bandolero

La canción se publica con la indicación: «con la música de Luis Pardo el bandolero». Pero el mensaje ha cambiado de manera significativa. A pesar de la melodía, el bandolero pierde sus rasgos románticos. Aparte de su «coraje y valor» ya no es sino un «bandido / que a un detective mató / cobardemente en un ómnibus / y que enseguida fugó». Desaparecen los caracteres positivos: es un «feroz delincuente». Conforme va avanzando la modernización, la figura del bandolero héroe se diluye para dejar solamente la del malhechor. El relato de sus fechorías ha desaparecido, la imagen romántica del héroe también. Estamos muy lejos de Luis Pardo, de sus hazañas y de sus buenas intenciones.

\section{Conclusión}

Las canciones sobre asesinos, truhanes y bandoleros han existido efectivamente en la cultura popular de la costa peruana: las páginas de $E I$ Cancionero de Lima lo evidencian. Pero se publican y difunden sobre todo 
entre 1910 y 1930, en una ciudad que no vive todavía la consolidación de los medios modernos de comunicación, la radio en particular. Su análisis muestra que la tradición oral sigue siendo un elemento importante de la vida social y la canción-relato, que sabe dar una forma y trasmitir una información, es mucho más que un instante de emoción. Siguiendo los códigos de comunicación del género, puede captar el acontecimiento y darle una existencia en el cuerpo social. Trátese de un asesinato, de una pelea entre maleantes, de la muerte de bandoleros, la canción dice, canta el evento, capta la sorpresa y le da una forma un estatuto, una dimensión específica. Permite su recepción por el grupo para el que ha sido creado. La canción es en este instante representación y acción. En el contexto en el que las condiciones de vida eran muy duras en esta Lima de la República Aristocrática, sigue siendo fiel a los cánones de la tradición oral hispánica marcada por la influencia del exemplum y ofrece una visión normativa del comportamiento social. 


\section{REFERENCIAS BIBLIOGRÁFICAS}

Basadre, J. (1980). Historia general de la República del Perú. Lima: Editorial Universitaria.

Borras, G. (2009). Chansonniers de Lima. Le vals et la chanson criolla (19001936). Rennes: PUR.

(2012). Lima, el vals y la canción criolla (1900-1936). Lima: Instituto de Etnomusicología (IDE-PUCP) e Instituto Francés de Estudios Andinos.

Lévano, E. (1998). Un cancionero escondido. Historia y música del Centro Musical Obrero de Lima: 1922-1924. Lima: Biblioteca Nacional del Perú.

Piel, J. (1982). Crise agraire et conscience créole au Pérou. París: CNRS.

Portocarrero Grados, R. (1998). El trabajo infantil en el Perú. Lima: Instituto de Formación para Educadores de Jóvenes, Adolescentes y Niños Trabajadores de América Latina y el Caribe.

Stein, S. (1986). Lima obrera, 1900-1930. Lima: Ediciones El Virrey.

Recepción: 22/02/2018

Aceptación: 29/03/2018 